\title{
Comparative Strengths of Four Organic Bases in Benzene ${ }^{1}$
}

\author{
Marion Maclean Davis and Hannah B. Hetzer
}

\begin{abstract}
Spectrophotometric studies have shown that the reaction of the base 1,3-di-o-tolylguanidine with the acidic indicator dye bromophthalein magenta E (tetrabromophenolphthalein ethyl ester) in benzene at $25^{\circ} \mathrm{C}$, like the reactions of 1,3-diphenylguanidine and 1,2,3-triphenylguanidine with the same indicator, can be represented by the following two equations:
\end{abstract}

$$
\begin{array}{r}
\underset{\text { (colorless base) }}{\mathrm{B}}+\underset{\text { (yellow acid) }}{\mathrm{HA}} \rightleftharpoons \underset{(\text { magenta salt) }}{\mathrm{BH}^{+} . \mathrm{A}^{-}} \\
\mathrm{BH}^{+} . \mathrm{A}^{-}+\mathrm{B} \rightleftharpoons \\
\left(\begin{array}{c}
\text { (blue salt) } \\
\text { (bH })^{+} \mathrm{A}^{-}
\end{array}\right.
\end{array}
$$

For ditolylguanidine, the equilibrium constants $K_{1}$ and $K_{2}$ for the first and second reactions, respectively, are estimated to be $1.1 \times 10^{6}$ and 6.4 . These values are compared with values for $K_{1}$ and $K_{2}$ previously found for di- and triphenylguanidine and the value of $K_{1}$ found for triethylamine.

The values for $K_{1}$, which measure the relative tendencies of the bases to form salts with the indicator acid in benzene, would be expected to parallel the ionic dissociation constants of the bases in water. However, the parallelism is not good. Diphenylguanidine and ditolylguanidine, which are presumed to be weaker bases in water than triethylamine, are much more reactive in benzene. The results demonstrate how misleading the aqueous dissociation constants may be as a gage of the relative reactivities of bases in a nonaqueous solvent such as benzene. Steric and solvation effects are discussed.

\section{Introduction}

Hantzsch and his coworkers were the first to demonstrate that acids that appear equally strong in aqueous solutions (for example, perchloric, hydrochloric, and nitric acids) display markedly different intrinsic strengths in organic solvents like chloroform and ether [1]. ${ }^{2}$

In their work, two kinetic methods and a static method were used in measuring the differences in strength. In the kinetic methods the differences in acidic strength were measured by the differing effects of the acids on the rate of inversion of cane sugar and on the rate of decomposition of diazoacetic ester. In the static method the relative strength of the acid was measured by the extent of salt-formation with an indicator dye or, what is in effect the same, by the stability of the salt upon dilution with an inert solvent. $p$-Dimethylaminoazobenzene is a yellow base that combines with acids to form fairly stable red salts; upon dilution with an "indifferent" solvent, such as chloroform or benzene, the salts decompose into the constituent acid and base to an extent that varies with the strength of the acid. This indicator was found suitable for comparisons of the strengths of weak or moderately strong acids. More weakly basic indicators (for example, dibenzalacetone and crystal violet) were used in the case of very strong acids, whose salts with dimethylaminoazobenzene were not measurably dissociated into the constituent acid and base even at very high dilutions. With the

\footnotetext{
1 Presented in part at the XIIth International Congress of Pure and Applied Chemistry, New York, N. Y. (Sept. 1951). The work was facilitated by a grant Chemistry, New York, N. Y. (Sept.
from the Office of Naval Research.

${ }_{2}$ Figures in brackets indicate the literature references at the end of this paper.
}

optical instruments then available, it was possible to make only roughly quantitative comparisons of acidic strengths. However, Hantzsch considered that in principle a chemical method, such as the indicator method, provides the most valid criterion of relative acidic strengths. Hantzsch also maintained that for many acids the strength, as measured by chemical reactivity, is diminished rather than increased by dilution with water. According to his views, water has a "leveling effect" on the strengths of acids because it combines with an acid, just as does a base, to form an "oxonium salt"; ionization, while a very important phenomenon, is a secondary effect that does not provide a scale of universal validity for the comparison of intrinsic acidic strengths. Hantzsch's methods and conclusions drew severe criticism, notably from von Halban[2]. However, as rigid application of the ionization theory of acidity and basicity has given way to the Brønsted-Lowry and Lewis concepts and as an increasing number of investigators have turned their attention to nonaqueous systems, it has become increasingly evident that Hantzsch's chemical criterion of tendency toward saltformation is fundamentally sound. Moreover, it is not in violent conflict with earlier views, as is sometimes supposed, but is in harmony with the concepts of acids, bases, and salts that have been most widely accepted during the development of chemistry as a science [3].

While the ionization theory of acidity and basicity was dominant, the custom developed of applying a common term, $\mathrm{pH}$, to aqueous solutions irrespective of whether the solute was an acid, a base, or a neutral salt. Later it became common practice to calculate 
the "acidity constant" for basic as well as for acidic compounds [4]. Thus, in the case of ammonia, the earlier representation of its strength by an ionization constant (approximately $1.8 \times 10^{-5}$ ) was succeeded by the use of the acidity constant (approximately $5.7 \times 10^{-10}$ ) for its "conjugate ion", the ammonium ion. The custom of expressing the strengths of both acids and bases in terms of acidity constants is perhaps one reason why the comparative strengths of acids have been studied more extensively than the comparative strengths of bases, not only in water but also in nonaqueous solvents. The neglect of bases has also resulted from the greater difficulties in their handling and purification.

Too few studies have been made for any estimate of a general leveling effect of water on the strengths of basic compounds, ${ }^{3}$ although one would expect to find that the intrinsic strengths of bases, like those of acids, are masked to some extent by water. TrotmanDickenson [5] has proposed a type of leveling effect as the reason why three separate equations, rather than a single equation, were required to express the relation between the catalytic power of a group of aniline bases for the decomposition of nitramide in anisole and the aqueous dissociation constants of the bases - one equation held for primary amines, a second held for secondary amines, and the third one held for tertiary amines. According to TrotmanDickenson's views, the ionic dissociation of amines in water is promoted by greater solvation of the cations as compared with solvation of the free amines. The solvation is considered to involve hydrogen bonding, the hydrogen of the bond being one of the ammonium hydrogens; stabilization by solvation will thus be greater for secondary ammonium ions than for tertiary ammonium ions, and greatest of all for primary ammonium ions. As a result, the dissociation constants measured in water (or in other hydrogen-bonding solvents) will indicate too great a strength for primary and secondary amines compared with that of tertiary amines; consequently, in experiments employing all three types of amines as catalysts in solvents of little or no hydrogen-bonding capacity, the proton-accepting powers of the amines cannot be related to the aqueous dissociation constants by a single equation.

Experiments performed with indicator dyes at this Bureau $[6,7,8]$ have provided other evidence of a leveling effect of water on bases. When an indicator dye is used in aqueous solutions to measure the $\mathrm{pH}$, changes in color do not depend on the nature of the acid or base added, but only on the strength and on the quantity. For example, in water bromophenol blue is yellow at a $\mathrm{pH}$ of 3.0 and purple blue at a $\mathrm{pH}$ of 4.6 , whatever the acid or base added. However, in benzene the color produced on the addition of a base is not the same for all bases but depends on its nature, as well as on its strength and on the quantity employed [7]. The different colors obtained in benzene, which were described in the references cited,

\footnotetext{
${ }^{3}$ In this paper, as in our pres ious papers, the term "base" refers chiefly to the neutral molecules of organic compounds that may be regarded as derivatives of ammonia, although the term, as broadly defined by both Bronsted and $\mathrm{G}$. N. Lewis, covers other types of suhstances, including many compounds containing
} oxygen, anions, and even certain cations. were attributed to different kinds of hydrogen bonding between bases and indicators. The absence of the differences in aqueous solutions is evidence that in water, in place of hydrogen-bonded complexes of different colors, all of the bases form hydrated cations.

Evidence of a third kind may be cited to show that the aqueous dissociation constants of bases provide only an imperfect guide to their behavior in media other than water. H. C. Brown and coworkers, in an exhaustive study of steric factors [9], have shown that the relative capacities of amines to combine in the gaseous phase with acids of the Lewis type (for example, trialkyl derivatives of boron $)^{4}$ depend on the "steric requirements" of the amine and the acid and not merely on the polar effect of substituents. Thus, when both the acid and the base are highly "hindered" (that is, have large steric requirements, owing to the presence of bulky substituents), the proportion of addition compound formed is less than when the acid is one of small steric requirements, such as the proton. In extreme cases, the acid and base fail to combine to any measurable extent.

From these few examples, it is clear that the behavior of a base is a function of its environment, from a qualitative as well as a quantitative standpoint. In view of the mounting industrial importance of organic bases, their numerous applications in catalyzing reactions, and their vital role in medicine, it is fortunate that they are becoming the subject of an increasing number of investigations.

The investigations of bases performed at this Bureau have had as their main purpose the development of methods for measuring acidity and basicity in organic solvents, particularly in the so-called "inert solvents" like benzene and other hydrocarbons. ${ }^{5}$ An incidental, but essential, part of the studies is finding out how bases of various classes behave in such solvents and the reasons for any unexpected phenomena. In one phase of the investigations, spectrophotometric studies have been made of reactions in which one of the reactants was an indicator dye. Some preceding publications [6 to 8] have dealt with the reactions of different organic bases with an acidic indicator dye named "bromophthalein magenta E" (the ethyl ester of tetrabromophenolphthalein). The most recent publication [8] was concerned with the reactions of 1,3-diphenylguanidine and 1,2,3-triphenylguanidine with this indicator. Previously [6] it had been found that arylguanidines such as these show the same pattern of behavior with the indicator as that of tertiary aliphatic amines $\left(\mathrm{R}_{3} \mathrm{~N}\right)$. Spectrophotometric evidence was presented [8] that the reaction

4 There appears to be a growing tendency in this country to employ the term "acid" in the general sense advocated by G. N. Lewis [10], treating the hvorogen acids as a special class of Lewis acids. Bell [11] has presented tne viewpoint of those who wish to retain the Bronsted- Bell [11] has presented tne viewpoint of those who wish to retain the Bronsted-Lowry definition of an acid, that is, to restrict the term "acid" to hydrogen acids (proton-donors), and who recommend hat the term "acceptor" (or "acceptor molecule") be applied to the remaining Lewis acids. However, as Bell has said [11], " . . . questions involved in the use of the terms acid and base are concerned essentially with convenience and con sistency, and not with any fundamental differences in the interpretation of experimental facts."

Recently there has been much interest in uncovering basic properties of benzene itself. However, benzene is an exceedingly weak base compared with water $12]$, and water in turn is much weaker as a base than the nitrogen compounds with which these studies are concerned. In such studies, benzene behaves as an inert, or differentiating, solvent, not as a leveling solvent [ 6 to 8 ]. 
of bases of this type with a monobasic, nonassociated acid HA in a solvent such as benzene can be represented by the equations

$$
\begin{gathered}
\mathrm{R}_{3} \mathrm{~N}+\mathrm{HA} \rightleftharpoons \mathrm{R}_{3} \mathrm{NH}^{+} . \mathrm{A}^{-} \\
\mathrm{R}_{3} \mathrm{~N}+\mathrm{R}_{3} \mathrm{NH}^{+} . \mathrm{A}^{-} \rightleftharpoons\left(\mathrm{R}_{3} \mathrm{NHNR}_{3}\right)^{+} \mathrm{A}^{-} .
\end{gathered}
$$

In the first step ("primary reaction") the proton of the acid $\mathrm{HA}$ is displaced toward the nitrogen of the base $\mathrm{R}_{3} \mathrm{~N}$ (although not transferred completely), yielding a salt $\mathrm{R}_{3} \mathrm{NH}^{+} . \mathrm{A}^{-}$(or $S_{1}$ ), which is, in effect, a highly polar addition compound. This reaction is analogous to the addition of a base $R_{3} \mathrm{~N}$ to a Lewis acid such as sulfur dioxide or a trialkyl boron. The "secondary reaction" (eq 2) involves rupture of the hydrogen bond between $\mathrm{N}$ and $\mathrm{A}$ and the formation of a new hydrogen bond between two nitrogen atoms. The secondary salt, $\left(\mathrm{R}_{3} \mathrm{NHNR}_{3}\right)^{+} \mathrm{A}^{-}$(or $\left.S_{2}\right)$, may be regarded as consisting of "ion pairs." 6

Upon application of a comparable sequence of reactions to the ionization of an acid (eq 3 to 5 ) and of an amine (eq 6 to 8 ) in aqueous solutions, one obtains

$$
\begin{aligned}
& \mathrm{H}_{2} \mathrm{O}+\mathrm{HA} \rightleftharpoons \mathrm{H}_{2} \mathrm{OH}^{+} . \mathrm{A}^{-} \\
& \text {base } \\
& \mathrm{H}_{2} \mathrm{O}+\mathrm{H}_{2} \mathrm{OH}+. \mathrm{A}^{-} \rightleftharpoons\left(\mathrm{H}_{2} \mathrm{OHOH}_{2}\right)^{+}+\mathrm{A}^{-} \\
& \text {base } \\
& 2 \mathrm{H}_{2} \mathrm{O}+\mathrm{HA} \rightleftharpoons\left(\mathrm{H}_{2} \mathrm{OHOH}_{2}\right)^{+}+\mathrm{A}^{-} \\
& \mathrm{R}_{3} \mathrm{~N}+\mathrm{HOH}_{2} \mathrm{R}_{3} \mathrm{NH}^{+} . \mathrm{OH}^{-} \\
& \mathrm{H}_{2} \mathrm{O}+\mathrm{R}_{3} \mathrm{NH}^{+} . \mathrm{OH}^{-} \rightleftharpoons\left(\mathrm{R}_{3} \mathrm{NHOH}_{2}\right)^{+}+\mathrm{OH}^{-} \\
& \text {base } \\
& \mathrm{R}_{3} \mathrm{~N}+2 \mathrm{H}_{2} \mathrm{O} \rightleftharpoons\left(\mathrm{R}_{3} \mathrm{NHOH}_{2}\right)^{+}+\mathrm{OH}^{-}
\end{aligned}
$$

The over-all reactions (eq 5 and 8 ) differ from the "classical" and Brønsted-Lowry formulations of such reactions in the following respects: (1) An additional molecule of water is involved; (2) the hydrogen ion is represented as being doubly hydrated; (3) the substituted ammonium ion is represented as being hydrated. The assumptions made in regard to hydration are in accordance with a variety of experimental evidence previously set forth [8]. Recent investigations by Rodebush have given further support to the proposed representation of the hydrogen ion as being doubly hydrated in aqueous solutions. ${ }^{7}$

We do not mean to imply, of course, that eq 3 to 5 and 6 to 8 are to be regarded as complete descriptions of the processes by which acids or amines become ionized in water. The behavior of water is so

\footnotetext{
${ }^{6}$ A mong various investigations that provide additional support for this twostep formulation are other spectrophotometric studies $[6,13]$, measurements of the variation of dielectric constant with con centration [14], conductance titrations [15], and studies of the properties of electrolytic sclutions in nonaqueous solvents $[16,17]$.

' W. H. Rodebush, at the Symposium on Hydrogen Bonds held by the Division of Physical and Inorganic Chemistry of the American Chemical Society at Cleveland, Ohio, on A pril 9,1951, stated that recent infrared studies have indicated that the hydrated proton should be represented as $\mathrm{H}_{2} \mathrm{OHOH}{ }_{2}+$ rather than as $\mathrm{H}_{3} \mathrm{O}^{+}$. Our eq 3 to 8 ignore possible hydration of the anions $\mathrm{A}^{-}$and $\mathrm{OH}^{-}$.
}

complex that no theory yet proposed accounts satisfactorily for all of its properties. However, such formulations are advantageous in several respects. In the first place, they bring out clearly that the fundamental step in the reaction of any hydrogen acid HA (water included) with a base is the formation of an addition compound. The formation of this addition compound involves displacement of the proton toward a molecule of the base, but for complete removal of the proton from the acid HA a second molecule of a base seems to be required [8]. The reactions involved in the ionization of acids or amines are thus seen to be manifestations of the tendency of the proton to form a bridge between electronegative atoms such as oxygen and nitrogen, new hydrogen bonds forming as previously formed hydrogen bonds are broken. Secondly, the cations formed in the over-all reactions (eq 5 and 8) are represented more accurately than in the classical formulation or in the BronstedLowry formulation, in view of the evidence that in aqueous solutions the proton is associated with at least two molecules of water and water molecules are coordinated with any hydrogen atoms attached to an ammonium nitrogen.

Furthermore, our concept of the fundamental, or "primary", reaction (eq 3 and 6) as an addition reaction provides a means of harmonizing the Brønsted-Lowry and Lewis definitions of acids. At the same time, our concept of the "secondary" reaction (eq 4 and 7 ) that may occur when the acid in question is a hydrogen (Brønsted-Lowry) acid emphasizes the distinctive behavior of the hydrogen acids that has its origin in the ability of the proton to form a bond between electronegative atoms. While the proposed formulations help to clarify the points of similarity and dissimilarity in the behavior of hydrogen acids and other compounds regarded as acids by Lewis, they do not impede the development of quantitative relationships among the hydrogen acids in aqueous solutions, as the over-all reactions (eq 5 and 8) differ from the Brønsted equations only in that an additional molecule of the solvent appears in our equations.

Finally, it should be clear from a consideration of eq 1 through 8 that the proper measure of the reactivity of an acid $\mathrm{HA}$ in a nonionizing medium such as benzene is the association constant for its reaction with some reference base (eq 1), and not a dissociation constant. The primary reaction measures the tendency of the proton to undergo displacement from $\mathrm{A}^{-}$toward a base, and this tendency would be expected to parallel the tendency in aqueous solutions for the proton to be separated completely from $\mathrm{A}^{-}$by conversion to a hydrated cation. Likewise, the proper measure of the reactivity of a base such as $\mathrm{R}_{3} \mathrm{~N}$ in a nonionizing medium is the association constant for its reaction with some reference acid. To be explicit, a primary acid-base association constant in benzene and other essentially inert solvents corresponds to an ionic dissociation constant in water, whereas we should expect to find inverse relationships between acid-base dissociation 
constants in benzene and ionic dissociation constants in water.

For two reasons the constant $K_{1}$ for the primary reaction is the proper criterion of reactivity in benzene rather than the constant $K_{2}$ for the secondary reaction (or the product $K_{1} K_{2}$ ): (1) In the secondary reaction both reactants vary when the nature of $R_{3} \mathrm{~N}$ varies. (2) Under favorable conditions $K_{1}$ can be measured with precision, but it is more difficult to ascertain the value of $K_{2}$ [8]. However, when the solvent (for example, water) plays the dual role of acid (eq 6) and of excess base (eq 7), the first objection does not hold. Furthermore, in such a solvent the criterion of reactivity is of necessity the overall reaction, as the primary and secondary reactions cannot be studied separately. ${ }^{8}$

In previous papers we have described the spectrophotometric determination of equilibrium constants for the primary reaction of bases with reference acids such as bromophthalein magenta E $[6,8]$, picric acid [13], and trinitro- $m$-cresol [13] in benzene. Of these three acids, bromophthalein magenta $\mathrm{E}$ is the most generally useful. In the determination of relative strengths, the reactions being compared must not proceed too far toward completion, and picric acid is too strong to serve as a reference acid for most of the aliphatic amines. Also, the positions and intensities of the absorption bands in reactions involving bromophthalein magenta $\mathrm{E}$ are such as to permit measurements of greater precision than can be attained with picric acid or trinitro- $m$-cresol. A dilute solution of bromophthalein magenta $\mathrm{E}$ (in the range of concentrations $10^{-5} M$ to $10^{-4} M$ ) has a yellow color, which shifts through tones of orange and red as minute, accurately measured increments of a base of the type $R_{3} \mathrm{~N}$ are added until a sufficient excess of the base has been added to drive the reaction essentially to completion, whereupon the color becomes magenta. From measurements of the absorption of such solutions at suitable wavelengths, the association constants are readily calculated. (The secondary reaction indicated by eq 2 occurs when a very large excess of base is added and is recognized by a shift in color from magenta toward blue.)

In this paper studies of the reaction of $1,3-\mathrm{di}-0$ tolylguanidine, $\mathrm{CH}_{3} \mathrm{C}_{6} \mathrm{H}_{4} \mathrm{NH}(\mathrm{C}=\mathrm{NH}) \mathrm{NHC}_{6} \mathrm{H}_{4} \mathrm{CH}_{3}$, with bromophthalein magenta $\mathrm{E}$ in benzene at $25^{\circ}$ $\mathrm{C}$ are described. Ditolylguanidine is one of the arylguanidines that react with bromophthalein magenta $\mathrm{E}$ in the same way as tertiary aliphatic amines $\left(\mathrm{R}_{3} \mathrm{~N}\right)$. One purpose of the studies was to check a provisional measurement of the association constant for the primary reaction [6]. A second object was to attempt to measure the constant for the secondary reaction. In the final portion of the paper the association constant for the primary reaction is compared with the constants previously found for the reaction of bromophthalein magenta $\mathrm{E}$

\footnotetext{
${ }^{8}$ It will be clear from the discussion that attempts to express the strength of bases in inert solvents like benzene in terms of "acidity constants", as is common practice for aqueous solutions, would lead to confusion.
}

in benzene with triethylamine, 1,3-diphenylguanidine, and 1,2,3-triphenylguanidine, and the relationship between the association constants in benzene and published ionization constants for the same bases in water is discussed.

\section{Equipment and Procedure}

As in preceding studies of the reaction of bromophthalein magenta $\mathrm{E}$ with bases $[6,8]$, the data were obtained with a Beckman Model DU quartz photoelectric spectrophotometer. However, the data given in this paper for ditolylguanidine were obtained with a recently purchased instrument, and the storage battery was operated from a power supply unit. ${ }^{9}$ The cell compartment, which was constructed of copper and brass parts in the Instrument Shop of the Bureau, was very similar to the thermostated air bath previously used [8, 18] except for a different arrangement for circulation of water through the bottom, side walls, and top. The outside of the compartment was plated with chromium over nickel; the interior was treated electrochemically to produce an optical black finish. ${ }^{10}$ In use, the temperature of the compartment varied from $25^{\circ} \mathrm{C}$ by less than $\pm 0.1 \mathrm{deg} \mathrm{C}$, while the temperature of the room was automatically controlled to stay between $24^{\circ}$ and $27^{\circ} \mathrm{C}$ but was usually between $24.5^{\circ}$ and $25.5^{\circ} \mathrm{C}$. The stock solutions were kept in the constant-temperature bath which controlled the temperature of the cell compartment. In other respects the equipment and procedure were as previously described.

The following terminology and symbols are used in the discussion and the figures: $\dot{C}_{s}, C_{a}$, and $C_{b}$ are the initial concentration of the salt, acid, and base respectively, in moles per liter; $[S],[A]$, and $[B]$ are the molar concentration of the salt, acid, and base, respectively, in an equilibrium mixture; $S_{1}$ is the primary salt, and $S_{2}$ is the secondary salt. $T_{s}$ (transmittancy of the solute) $=T_{\text {soln }} / T_{\text {solv }} ; A_{s}$ (absorbancy of the solute) $=-\log _{10} T_{s} ; a_{M}$ (molar absorbancy index $=A_{s} / b M$, where $b$ is the length in centimeters of the absorption cell, and $M$ is the concentration of the solute in moles per liter of solution.

\section{Materials}

The purification of the benzene and the preparation and purification of bromophthalein magenta $\mathrm{E}$ were described previously [6]. A commercial grade of di-o-tolylguanidine, the neutralization equivalent of which indicated the presence of 1.1 percent of inert impurity, was recrystallized twice from 95percent ethanol, washed with benzene, air-dried overnight, then dried in a vacuum oven at approximately $66^{\circ} \mathrm{C}$. After recrystallization, the melting point was $175.8^{\circ}$ to $176.3^{\circ} \mathrm{C}$, and the titration of three successive samples gave the following values for the

${ }^{9}$ Manufactured by the Fisher Scientific Company.

10 The cell compartment and accessory cell holders were constructed by Vernon L. Mix, who, together with Raymond Davis and E. R. Smith, made many helpful suggestions. The electroplating was done in the Electrodeposition Section of the Bureau. 
purity, expressed as percentage: 99.87, 100.01, 99.99. In the titrations, samples weighing approximately 0.5 to $0.7 \mathrm{~g}$ were dissolved in redistilled 95 -percent ethanol and titrated with approximately $0.1-N$ standard aqueous hydrochloric acid, with an aqueous mixture of methyl red sodium salt and alphazurine [19] as indicator.

\section{Data and Discussion}

\subsection{The Primary Reaction of Bromophthalein Magenta E with 1,3-Di-o-tolylguanidine}

The progressive changes in spectral absorption that accompany the primary reaction of bromophthalein magenta $\mathrm{E}\left(2.5 \times 10^{-5}-M\right.$ in benzene, $5-\mathrm{mm}$ absorption cells) with ditolylguanidine are illustrated in figure 1. The absorption curves were measured over the wavelength region extending from $320 \mathrm{~m} \mu$ to the longest wa veleng th at which there was measurable absorbancy. ${ }^{11}$ Curve $\mathrm{A}$ is for the indicator without added base, and curves 1 to 3 are for its mixtures with approximately $7.3 \times 10^{-6}-M, 1.45 \times$ $10^{-5}-M$, and $2.18 \times 10^{-5}-M$ ditolylguanidine, respectively. When the concentration of ditolylguanidine was progressively increased in the range from $2.5 \times 10^{-4} M$ (10 moles of base to 1 mole of indicator) to $10^{-3} M$ (40 moles of base to 1 mole of indicator), the successive absorption curves showed no measurable difference. The curve for the solution that contained $6.25 \times 10^{-4}-M$ ditolylguanidine $(25$ molar equivalents) was adopted as the limiting curve for the primary reaction and is shown as $S_{1}$ in figure 1 and subsequent figures.

Well-marked isosbestic points occur near 355 and $455 \mathrm{~m} \mu$ just as in the reactions of bromophthalein

11 Absorption in this region is ascribed to the indicator and its magenta salt. A benzene solution of ditolylguanidine in a 5-mm absorption cell does not show measurable absorption at wavelengths longer than approximately 390 to $400 \mathrm{~m} \mu$, even at a concentration as great as $0.02-M$. The absorption due to ditolylguanidine is probably shifted slightly toward shorter wavelengths when it combines with bromophthalein magenta $\mathrm{E}$ to form the magenta salt. When the concentration of ditolylguanidine in the solution was $1.25 \times 10^{-4}-M$ or greater, the same quantity was placed in both absorption cells; when the concentration was smaller, benzene was used in the reference cell.

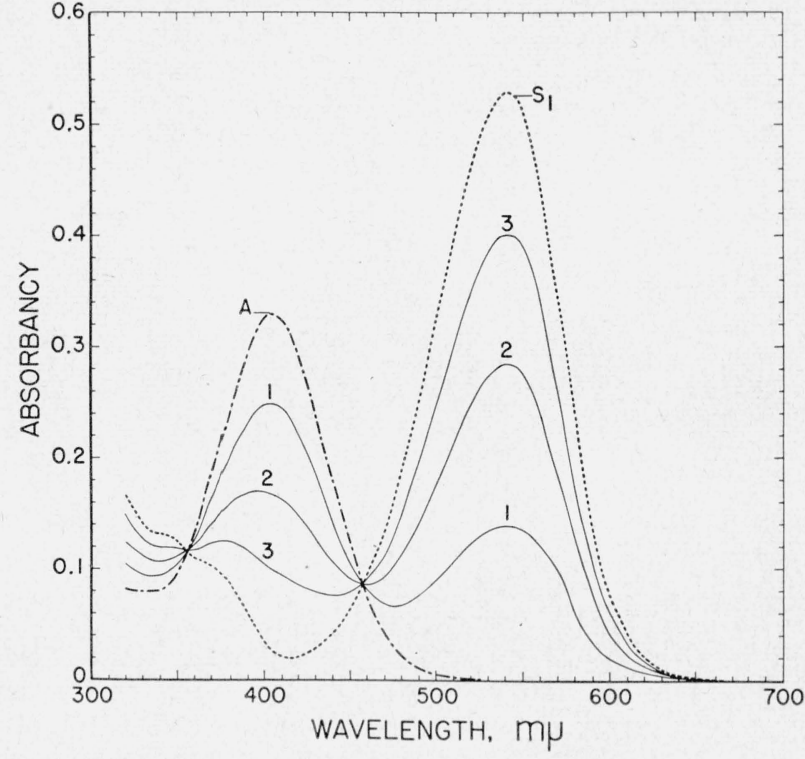

FIGURE 1. Changes in absorbancy accompanying the primary reaction of bromophthalein magenta $E, 2.5 \times 10^{-5}-M$ in benzene, with di-o-tolylguanidine.

A, BPM-E without added base; 1 to 3 , with approximately $7.3 \times 10^{-6}-M$, $1.45 \times 10^{-5}-M$, and $2.18 \times 10^{-5}-M$ base, respectively; $S_{1}$, with $6.25 \times 10^{-4}-M$ base (limiting curve).

magenta $\mathrm{E}$ with other bases of this type $[6,7]$ and, as is usual, are regarded as satisfactory evidence of the absence of side reactions.

The data used in the calculation of the primary association constant and the calculated values are presented in table 1 . The association constant is the equilibrium constant corresponding to eq 1 , which, with a different choice of symbols, is the same as

$$
\mathrm{A} \text { (acid) }+\mathrm{B} \text { (base) } \rightleftarrows \mathrm{S}_{1} \text { (primary salt). }
$$

From measurements at $540 \mathrm{~m} \mu$, the calculated association constant $\left(K_{1}\right.$ or $\left.K_{\text {assn. }}\right)$ is $1.1 \times 10^{6}$; from measurements at $405 \mathrm{~m} \mu$, the value is $1.0 \times 10^{6}$. In a parallel series of measurements with different stock

TABLE 1. Experimental data and association constant for the primary reaction of bromophthalein magenta $E$ with 1,3-di-o-tolylguanidine in benzene

\begin{tabular}{|c|c|c|c|c|c|c|}
\hline \multirow{3}{*}{$C_{b}{ }^{a}$} & \multicolumn{6}{|c|}{ From measurements at- } \\
\hline & \multicolumn{5}{|c|}{$540 \mathrm{~m} \mu$} & $405 \mathrm{~m} \mu$ \\
\hline & $A_{8} \mathrm{~b}$ & {$\left[S_{1}\right]^{a}$} & {$[A]^{\mathrm{a}} \mathrm{\circ}$} & {$[B]^{\mathrm{a}}$} & $K_{\mathrm{sssn}}$ & $K_{\mathrm{as8n}}$ \\
\hline \multirow[t]{2}{*}{$\begin{array}{l}1.25 \times 10^{-5} \\
1.5 \\
1.75 \\
1.875 \\
2.0 \\
2.125 \\
2.25 \\
2.5 \\
2.75 \\
3.0 \\
\text { Limiting vaiue }\end{array}$} & \multirow[t]{2}{*}{$\begin{array}{r}0.2482 \\
.2914 \\
.3309 \\
.3546 \\
.3732 \\
.3957 \\
.4112 \\
.4428 \\
.4656 \\
.4773 \\
.5287\end{array}$} & \multirow[t]{2}{*}{$\begin{array}{l}1.174 \times 10^{-5} \\
1.378 \\
1.565 \\
1.677 \\
1.765 \\
1.871 \\
1.944 \\
2.094 \\
2.202 \\
2.257 \\
2.500\end{array}$} & $\begin{array}{l}1.326 \times 10^{-5} \\
1.122 \\
0.935 \\
.823 \\
.735 \\
.629 \\
.556 \\
.406 \\
.298 \\
.243\end{array}$ & $\begin{array}{l}0.076 \times 10^{-5} \\
.122 \\
.185 \\
.198 \\
.235 \\
.254 \\
.306 \\
.406 \\
.519 \\
.743\end{array}$ & $\begin{array}{l}1.16 \times 10^{6} \\
1.01 \\
0.90 \\
1.03 \\
1.02 \\
1.17 \\
1.14 \\
1.27 \\
1.35 \\
1.25\end{array}$ & $\begin{array}{l}0.85 \times 10^{6} \\
.90 \\
.81 \\
.96 \\
.93 \\
1.03 \\
0.99 \\
1.11 \\
1.07 \\
1.10\end{array}$ \\
\hline & & & & Avg & 1. $13 \times 10^{6}$ & $0.98 \times 10^{6}$ \\
\hline
\end{tabular}

a In moles per liter of solution.

$b$ Calculated from the average of 10 readings of the transmittancy.

c $C_{\mathrm{s}}=2.5 \times 10^{-5} \mathrm{~mole}$ per liter. 5 -mm cells. 
solutions and slightly different concentrations of ditolylguanidine, the same values were obtained. The value for $540 \mathrm{~m} \mu$ is probably the better, as any errors are likely to be greater at $405 \mathrm{~m} \mu$ where two limiting values have to be determined (one for the indicator, as well as one for the salt). The changes in absorption are also greater at $540 \mathrm{~m} \mu$ and correspond to a more suitable range of absorbancies. There is evidence that ditolylguanidine, like other bases, is adsorbed to a very small extent on glass (probably in a monomolecular layer); the error caused by such adsorption (or actual salt-formation with silicic acid groups in the glass) would vary with the extent of contact of the various solutions with fresh glass surfaces during their preparation and would be greatest for the solutions that contain the smallest concentrations of ditolylguanidine. (For this reason the data obtained for concentrations of ditolylguanidine less than $1.25 \times 10^{-5} \mathrm{M}$ were not included in the computation of $K_{\text {assn. }}$ ) The association constant could be measured with greater precision if ditolylguanidine combined less readily with bromophthalein magenta E; even at the "limiting" concentration for the reaction, the ditolylguanidine is less than $10^{-3}-M$ in concentration. However, we believe that when all conceivable sources of error are taken into account, the value obtained for the association constant is well within \pm 10 percent of the correct value. The provisional value $0.63 \times 10^{5}$, found in earlier exploratory studies [6] probably indicates that a small amount of inert material was present in the sample of ditolylguanidine used at that time. The ditolylguanidine had been recrystallized twice from benzene (a method of purification that had proved satisfactory for diphenylguanidine), but its purity was not checked by titration. Later it was found for a different sample of ditolylguanidine that a satisfactory neutralization equivalent could be obtained by recrystallization of the commercial material from ethanol, but not by recrystallization from benzene.

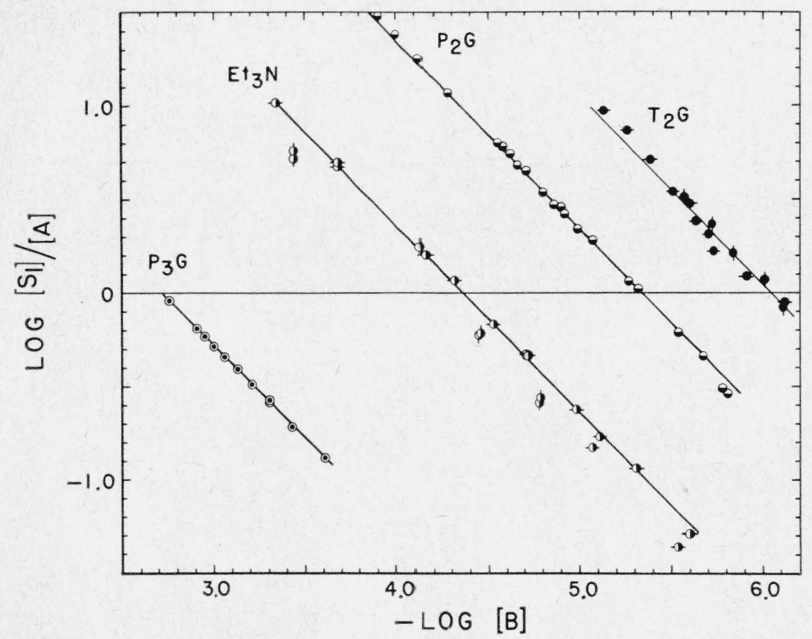

FIgURE 2. Graphical evaluation of association constants for the primary reaction of bromophthalein magenta $E$ with bases in benzene.

$\mathrm{P}_{3} \mathrm{G}, 1,2,3$-triphenylguanidine; Et ${ }_{3} \mathrm{~N}$, triethylamine; $\mathrm{P}_{2} \mathrm{G}, 1,3$-diphenylguanjdine; $\mathrm{T}_{2} \mathrm{G}$, 1,3-di-0-tolylguanidine.
Graphical evaluation of the association constant is shown in figure 2. The association constant for the primary reaction in logarithmic terms can be expressed by the equation

$$
\log \left[S_{1}\right] /[A]-\log [B]=\log K_{\text {assn. }}
$$

In figure $2, \log \left[S_{1}\right] /[A]$ is plotted against $-\log [B]$. The theoretical curve is a straight line of slope -1. $\log K_{\text {assn }}$ is the intercept on the horizontal axis for $\log \left[S_{1}\right] /[A]=0$. The solid circles near the line marked $T_{2} G$ indicate the values obtained for the primary reaction of bromophthalein magenta E with ditolylguanidine. The values from the two parallel experiments are distinguished by the vertical or horizontal lines through the solid circles. The symbols $P_{3} G, \quad E t_{3} N$, and $P_{2} G$ indicate previous results $[6,8]$ for the reaction of bromophthalein magenta $\mathrm{E}$ with triphenylguanidine, triethylamine, and diphenylguanidine, respectively; the corresponding association constants were found to be 525 , $2.3 \times 10^{4}$, and $2.2 \times 10^{5} .{ }^{12}$

\subsection{The Secondary Reaction of Bromophthalein Magenta E with Di-o-tolylguanidine}

As mentioned earlier, the secondary reaction of bromophthalein magenta $\mathrm{E}$ in benzene with bases of this type (eq 2) is indicated by a shift in the color of the solution from magenta toward blue. In the reaction of $2.5 \times 10^{-5}-M$ bromophthalein magenta $\mathrm{E}$ with ditolylguanidine, the rate of change with increasing concentration of the base was smaller than in the case of the reaction of bromophthalein magenta $\mathrm{E}$ with diphenylguanidine. Furthermore, the measurements could not be extended to such high concentrations of the base, because ditolylguanidine is less soluble in benzene than diphenylguanidine. ${ }^{13}$ In figure 3 is shown the change in the absorption curve that accompanied an increase in the concentration of ditolylguanidine from $6.25 \times 10^{-4}$ $M$ (curve $S_{1}$ ) to $0.02178-M$ (curve 2). Enlarged sections of these two curves in the wavelength range 500 to $600 \mathrm{~m} \mu$ and a portion of the curve for a solution that contained $0.01-M$ ditolylguanidine are shown in figure 4 . The three curves in figure 4 intersect near $547.5 \mathrm{~m} \mu$; curves for solutions that contained intermediate concentrations of ditolylguanidine had the same isosbestic point. Study of the curves reveals that as the absorption near $540 \mathrm{~m} \mu$ decreases, the most marked increase in absorption occurs near $585 \mathrm{~m} \mu$, which is probably the approximate location of the head of the main

12 The association constant $2.3 \times 10^{4}$ obtained for the reaction of triethylamine with bromophthalein magenta is a provisional value but is thought to be very close to the true value, although the measurements were made before the ther mostated cell compartment had been obtained. Preliminary measurements with bromophthalein magenta $\mathrm{E}$ are indicated by the circles intersected by vertical lines; the remaining circles, with horizontal intersecting lines, indicate a more complete series of measurements with bromophthalein magenta B (the complete ser es $n$-butyl ester of tetrabromert controlled conditions. We believe that under the most favorable experimenta conditions the association constant would be found to be exactly the same for the reaction of triethylamine with bromophthalein magenta $\mathrm{E}$ as for its reaction with
bromophthalein magenta $\mathrm{B}$. romophthalein magenta $\mathrm{B}$

${ }_{13}$ A $0.022-M$ solution of ditolylguanidine is near the limit of solubility in benzene at $25^{\circ} \mathrm{C}$, while $0.07-M$ diphenylguanidine and $0.25-M$ triphenylguanidine were prepared without difficulty. 


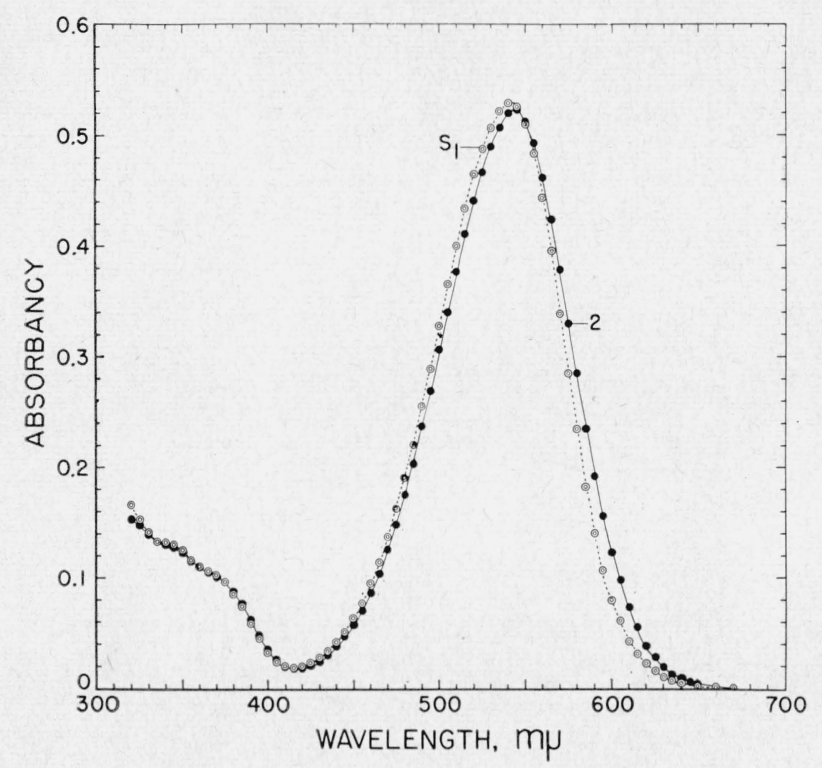

Figure 3. Changes in absorbancy accompanying the secondary reaction of bromophthalein magenta $\mathrm{E}, 2.5 \times 10^{-5}-\mathrm{M}$ in benzene, with di-o-tolylguanidine.

$S_{1}$, BPM-E with $6.25 \times 10^{-4}-M$ base (limiting curve for primary reaction); 2 , with $0.02178-M$ base.

absorption band of the secondary salt, $S_{2}$. When several solutions in this series were tested after standing for about a month, the absorption curves were the same as those obtained within an hour or two after preparation of the solutions.

As previously found for diphenyl- and triphenylguanidine [8], further shifts in the absorption curves toward longer wavelengths occur when the concentration of both the indicator and the base are greatly increased. The changes are illustrated in figure 5. The shapes of the curves indicate that an absorption curve with a strong band near $585 \mathrm{~m} \mu$ is changing to a curve with a strong band in the vicinity of $600 \mathrm{~m} \mu$. We believe this change to be caused by aggregation of molecules of the secondary salt. When an attempt was made to prepare a solution with $0.003-M$ indicator (bromophthalein magenta B) and $0.006-M$ base, it was evident that the limit of the solubility of the salt had been exceeded.

An over-all picture of the primary and secondary reactions is presented in figure 6 . The changes in absorbancy at two wavelengths, $580 \mathrm{~m} \mu$ (curve 1a) and $590 \mathrm{~m} \mu$ (curve 1b) are plotted against the square root of the concentration of ditolylguanidine (which is again expressed as molar equivalents of the indicator). With minute additions of the base, the absorption at first increases rapidly; this is the region of the primary reaction. At intermediate concentrations, there is no measurable change. At high concentrations of the base, the absorption again shows a measurable, although slow rise; this is the region of the secondary reaction. Dotted lines 2a and $2 \mathrm{~b}$ show corresponding changes in the secondary reaction of bromophthalein magenta $\mathrm{E}$ with diphenylguanidine; the rate of change is

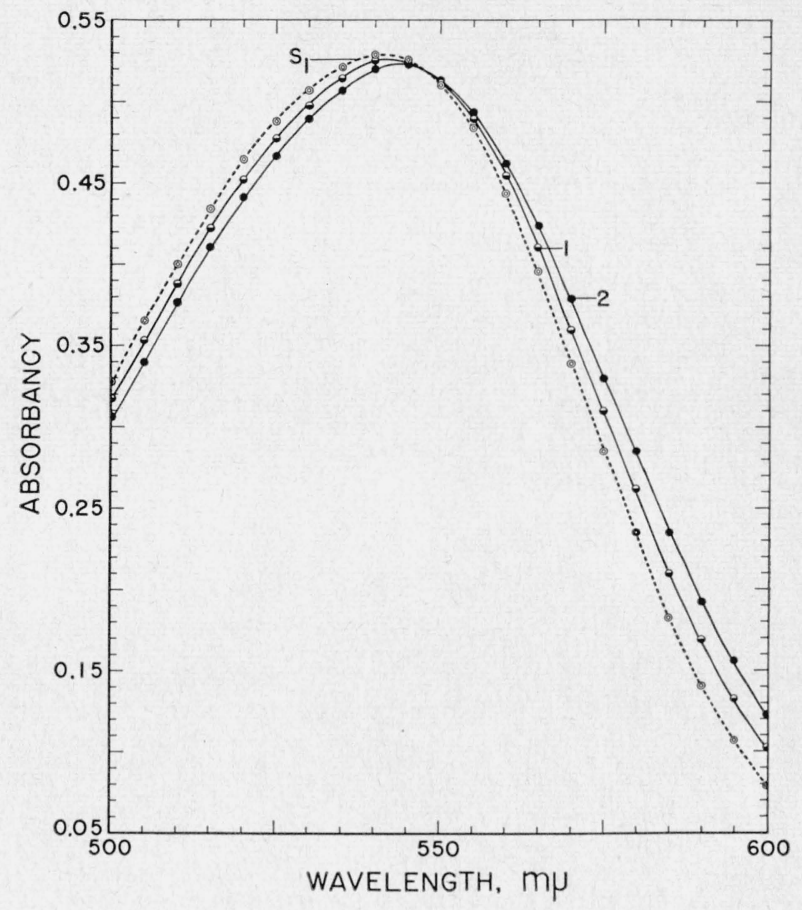

FIgURE 4. Changes in absorbancy accompanying the secondary reaction of bromophthalein magenta $E, 2.5 \times 10^{-5}-M$ in benzene, with di-o-tolylguanidine.

$S_{1}$, BPM-E with $6.25 \times 10^{-4}-M$ base (limiting curve for primary reaction); 1 , with $0.01-M$ base; 2 , with $0.02178-M$ base. Curves $S_{1}$ and 2 are enlarged sections of curves $S_{1}$ and 2 in figure 3 .

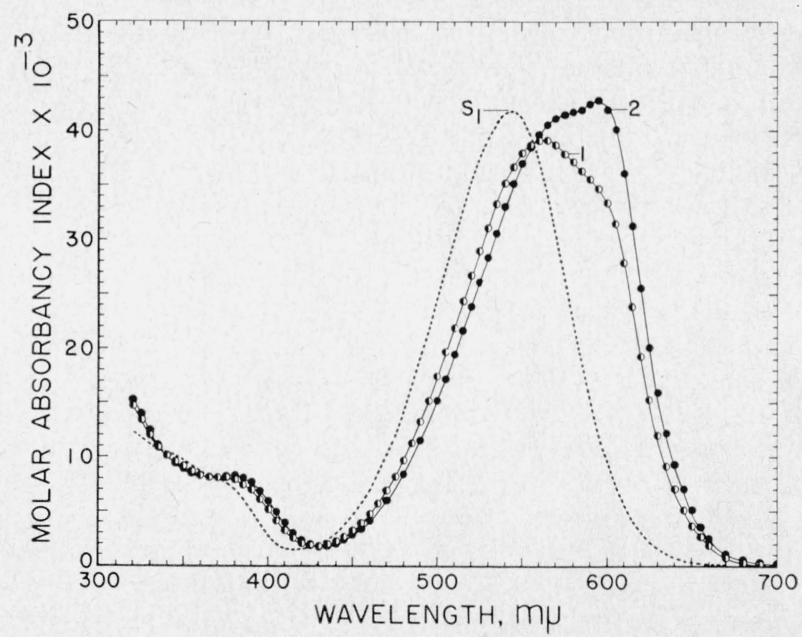

FIgURE 5. Changes in the molar absorbancy of benzene solutions with variation in the concentration of both bromophthalein magenta $E$ and di-o-tolylguanidine.

$S_{1}, 2.5 \times 10^{-5}-M$ BPM-E with $6.25 \times 10^{-4}-M$ base; $1,1.25 \times 10^{-3}-M$ BPM-E with $0.011-M$ base; $2,2.0 \times 10^{-3}-M$ BPM-E with $0.004-M$ base.

clearly appreciably greater for diphenylguanidine than for ditolylguanidine. If data for $540 \mathrm{~m} \mu \mathrm{had}$ been plotted on this figure, they would have shown a steeper rise in the region of the primary reaction, a plateau in the same region as those in curves 1a and $1 b$, and a very slow decrease in absorbancy in the region of the secondary reaction. 


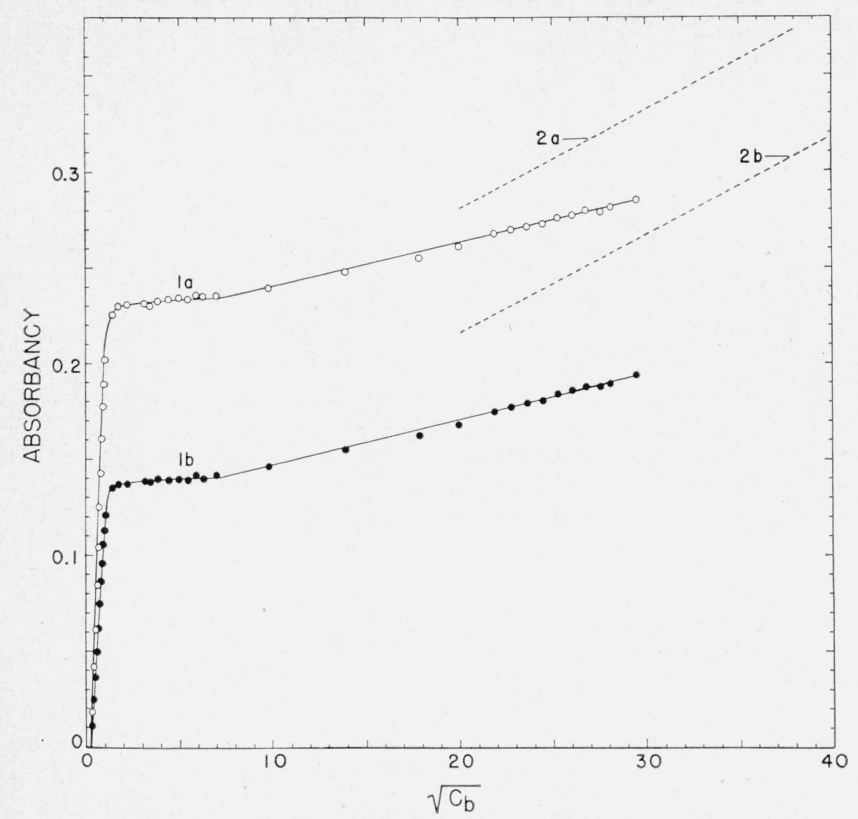

Figure 6. Changes in absorbancy at two wavelengths accompanying the primary and secondary reactions of $2.5 \times 10^{-5}-M$ bromophthalein magenta $E$ with 1, di-o-tolylguanidine and 2 , diphenylguanidine in benzene.

5-mm cells. a, $580 \mathrm{~m} \mu ; \mathrm{b}, 590 \mathrm{~m} \mu . \quad C_{b}$ is the concentration of the base ex pressed as molar equivalents of $\mathrm{BPM}-\mathrm{E} ;[B] \simeq C_{b}$.

From what has been said, it is obvious that the limiting curve for the secondary reaction of bromophthalein magenta $\mathrm{E}$ with di-o-tolylguanidine could not be obtained experimentally. In the previous experiments with diphenylguanidine [8], it was possible to work at higher concentrations of the base, and, as already mentioned, the absorbancy at the longer wavelengths changed more rapidly with increase in the concentration of base as the magenta primary salt was converted to the blue secondary salt. By trial and error a limiting value was found that gave a series of 10 values of $K_{2}$ in very good agreement, with the average value 15.5. Because the increments in absorbancy, which of course had to be measured on steep portions of the curves (see figs. 3 and 4), were so much smaller in the case of ditolylguanidine in the limited range of concentrations that could be studied, it was not possible to estimate the limiting value with as high a degree of certainty. However, it is reasonable to assume, for a rough approximation, that for two such closely related bases as diphenyl- and ditolylguanidine the limiting value of the absorbancy for the secondary salt would be the same. On the assumption of the same limiting value (0.680) for the two secondary salts, the values in table 2 were calculated. The method of calculation was the same as that described in [8]. The values thus obtained for the secondary association constant $K_{2}$, given in the last column, range from 5.9 to 6.8 , with the average value 6.4 .

A graphical evaluation of the secondary association constant $K_{2}$ is shown in figure 7 . The symbols $T_{2} G, P_{2} G$, and $P_{3} G$ have the same significance as in

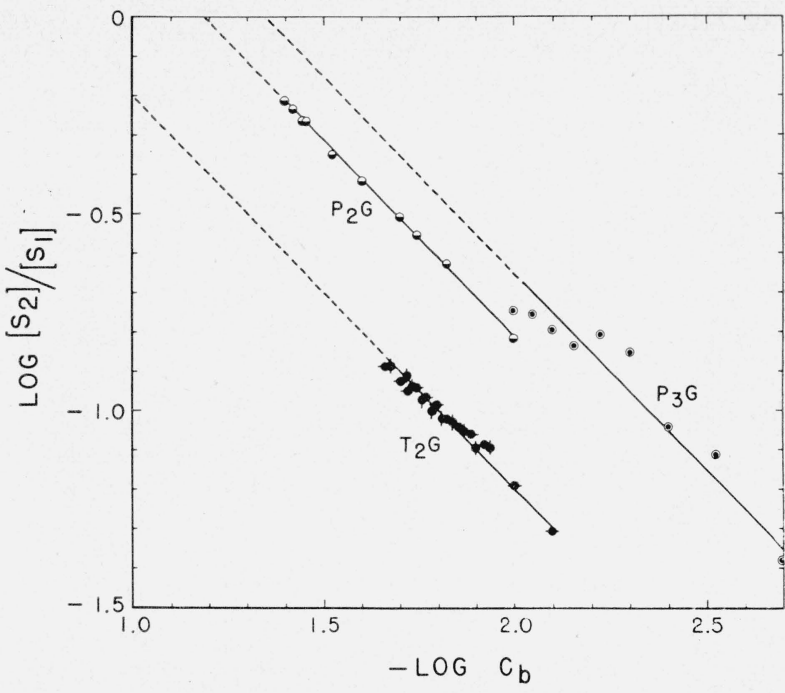

FIGURE 7. Graphical evaluation of equilibrium constants for the secondary reaction of bromophthalein magenta $E$ with bases in benzene.

$\mathrm{T}_{2} \mathrm{G}$, 1,3-di-o-tolylguanidine; $\mathrm{P}_{2} \mathrm{G}$, 1,3-diphenylguanidine; $\mathrm{P}_{3} \mathrm{G}$, 1,2,3-triphenylguanidine.

TABLE 2. Experimental data and association constant for the secondary reaction of bromophthalein magenta $E$ with di-otolylguanidine in benzene

\begin{tabular}{|c|c|c|c|c|c|c|}
\hline$C_{b}{ }^{a}$ & $A_{8}{ }^{b}$ & $\Delta A_{s} c$ & $z-A_{8} d$ & $\begin{array}{c}-\log \\
\left(S_{2} / S_{1}\right)\end{array}$ & $-\log C_{b} a$ & $K_{2}{ }^{e}$ \\
\hline $\begin{array}{l}0.008 \\
.010 \\
.012 \\
.013 \\
.014 \\
.015 \\
.016 \\
.017 \\
.018 \\
.019 \\
.0198 \\
.02178\end{array}$ & $\begin{array}{l}0.2553 \\
.2614 \\
.2681 \\
.2701 \\
.2716 \\
.2732 \\
.2762 \\
.2779 \\
.2802 \\
.2794 \\
.2818 \\
.2857\end{array}$ & $\begin{array}{r}0.0209 \\
.0270 \\
.0337 \\
.0357 \\
.0372 \\
.0388 \\
.0418 \\
.0435 \\
.0458 \\
.0450 \\
.0474 \\
.0513\end{array}$ & $\begin{array}{r}0.4247 \\
.4186 \\
.4119 \\
.4099 \\
.4084 \\
.4068 \\
.4038 \\
.4021 \\
.3998 \\
.4006 \\
.3982 \\
.3943\end{array}$ & $\begin{array}{l}1.308 \\
1.190 \\
1.087 \\
1.060 \\
1.041 \\
1.021 \\
.985 \\
.966 \\
.941 \\
.950 \\
.924 \\
.886\end{array}$ & $\begin{array}{l}2.097 \\
2.000 \\
1.921 \\
1.886 \\
1.854 \\
1.824 \\
1.796 \\
1.770 \\
1.745 \\
1.721 \\
1.703 \\
1.662\end{array}$ & $\begin{array}{l}6.2 \\
6.5 \\
6.8 \\
6.7 \\
6.5 \\
6.4 \\
6.5 \\
6.4 \\
6.4 \\
5.9 \\
6.0 \\
6.0\end{array}$ \\
\hline A vg & & & & & & 6.4 \\
\hline
\end{tabular}

s Initial molar concentration of di-o-tolylguanidine. $[B] \cong C_{b}$.

b Absorbancy at $580 \mathrm{~m} \mu$, calculated from the average of 10 readings of the transmittancy

c $\Delta A_{8}=A_{s}-0.2344: 0.2344$ is the limiting value found for the primary salt at $580 \mathrm{~m} \mu$ when $2.5 \times 10^{-5}-M$ in 5 -mm cell.

$\mathrm{d} z$, the assumed limiting value for the secondary salt $\left(S_{2}\right)$ at $580 \mathrm{~m} \mu=0.680$; $\Delta A_{s} /\left(z-A_{s}\right)=S_{2} / S_{1}$

figure 2, as also do the horizontal and vertical lines through the solid circles. The construction of figure 7 is analogous to that of figure 2. Figure 7 indicates how close all the values for diphenylguanidine are to a straight line of the theoretical slope -1 . There is much greater uncertainty about the value of the $K_{2}$ for the reaction of triphenylguanidine with bromophthalein magenta E [8]. However, the tendency for the secondary reaction to occur appears to be in the reverse order of the magnitude of the primary association constant.

\subsection{Discussion}

The values given in section 4.1 for the primary association constants $\left(K_{1}\right.$ or $K_{\mathrm{assn}}$ ) for the reaction of bromophthalein magenta $\mathrm{E}$ in benzene with the 
bases discussed in this paper place the bases in the following order of increasing strength: (1) triphenylguanidine, (2) triethylamine, (3) diohenylguanidine, (4) di-o-tolylguanidine. It is of interest to compare the relative association constants for the four bases in benzene with their ionic dissociation constants $K_{b}$ in water. This comparison can be made from figure 8 , in which $\log K_{\text {dissn. }}\left(\log K_{b}\right)$ in water is plotted against $\log K_{\text {assn. in benzene. }}{ }^{14}$ For each axis, the lowest values are those nearest the origin. Therefore, if the tendency toward salt-formation in benzene paralleled the extent of ionization in water, the values for the four bases should fall on or close to a line of positive slope. It is obvious that they do not do so. (In fact, for the three strongest bases one might suspect an inverse relationship.) The figure also shows clearly that the values vary over a greater range in benzene than in water.

One of the purposes of studies such as these is to ascertain the causes of any lack of uniformity in the behavior of bases with different acids and in different solvents, in order that acid-base behavior may be predicted as well as understood. Although a complete interpretation of our data must await the accumulation of knowledge from more extensive experimentation, it is possible to draw some tentative conclusions. The first point to consider, however, is the possibility that any of the constants are unreliable. As to the association constants determined in benzene, we believe that any conceivable errors in the values would not affect their relative order of magnitude. There is also probably no question about the relative magnitudes of the aqueous ionization constants for triethylamine, diphenylguanidine, and triphenylguanidine. The aqueous dissociation constant for di-o-tolylguanidine was determined by Metz [20], who also measured the ionization constant for diphenylguanidine and adopted for it a value slightly greater than that for ditolylguanidine (although slightly lower than the accepted value). Metz did not claim high accuracy for his measurements, and his values for different concentrations are not in close agreement. From a scrutiny of his data no conclusion appears warranted other than that diphenyl- and di-o-tolylguanidine are of about the same basicity in water. Perhaps the same value $(-4.0)$ should have been used for both bases in the construction of figure 8 . However, a more precise measurement of the basicity of di- $o$-tolylguanidine in water is desirable.

The effects of substituents on the basicity of guanidine have been studied by Davis and Elderfield [21], Hall and Sprinkle [22], Wheland and coworkers [23], and Angyal and Warburton [24]. The high basicity of guanidine, which approaches that of sodium and potassium hydroxides [21, 22] has been explained by the resonance hypothesis [25, p. 212]; that is, the guanidinium ion, because it resonates

\footnotetext{
14 The values for $\log K_{\text {disan. }}$ in water were taken from the publications indicated in [6], table 2. For triethylamine, diphenylguanidine, ditolylguanidine, and triphenylguanidine, in the order named, these values are $-3.28,-4.0,-4.33$, and -4.9 . (The value for ditolylguanidine was obtained at $18^{\circ} \mathrm{C}$, the other
} values at $25^{\circ} \mathrm{C}$.)

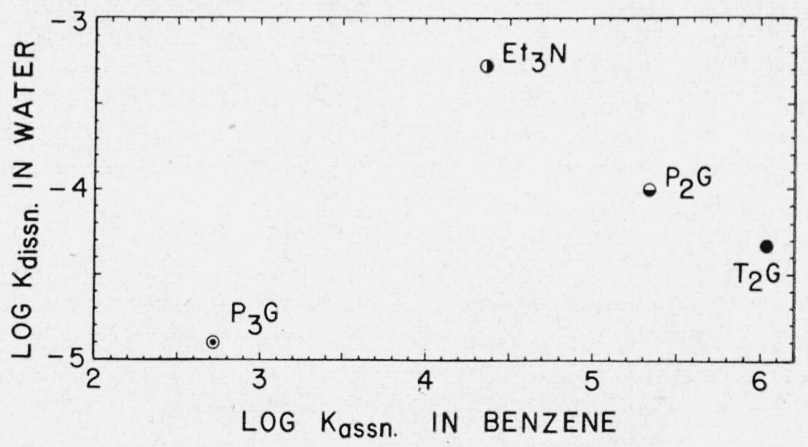

Figure 8. Comparative strengths of bases as measured by association with bromophthalein magenta $E$ in benzene and by ionic dissociation constants in water.

$\mathrm{P}_{3} \mathrm{G}$, 1,2,3-triphenylguanidine; $\mathrm{Et} \mathrm{t}_{3} \mathrm{~N}$, triethylamine; $\mathrm{P}_{2} \mathrm{G}$, 1,3-diphenylguanidine; $\mathrm{T}_{2} \mathrm{G}, 1,3$-di-o-tolylguanidine.

among three equivalent structures, is more stable than guanidine, which resonates among three structures of which only two are equivalent. Replacement of one or more of the hydrogens by alkyl groups has almost no effect on the strength in water $[21,23,24]$. However, the basicity in water is progressively weakened as phenyl groups are introduced in the 1-, 1,3-, and 1,2,3-positions [22]. ${ }^{15}$ On the resonance hypothesis, a reduction in the basicity by the introduction of phenyl groups is to be expected, because phenyl derivatives of guanidine are also derivatives of aniline, and the nitrogen atoms will be involved in resonance with the benzene rings just as in aviline $\left[25\right.$, p. 206] ${ }^{16}$ The greater reactivity of di-o-tolylguanidine, as compared with diphenylguanidine, with the acid bromophthalein magenta E in benzene may result from the effect of the ortho methyl substituents in reducing the aniline type of resonance. As just noted, the aniline type of resonance would have a base-weakening effect; steric inhibition of this resonance should have a basestrengthening effect. If this line of reasoning is correct, still greater reactivity should be found for compounds such as 1,3-dimesitylguanidine, in which the aniline groups have substituents in all ortho positions. Strong bases are needed for titrations of weak acids in nonaqueous solvents, and various derivatives of guanidine are worthy of attention in this connection. Although the only available value for di-o-tolylguanidine [20] is of too provisional a character to justify a final decision as to the relative basicities of diphenylguanidine and di-o-tolylguanidine in water, the similarity of Metz's results for the

15 The numbering of substituents conforms to the following formula for the parent compound, guanidine: $\mathrm{H}_{2} \mathrm{~N} \cdot \mathrm{C}(=\mathrm{NH}) \cdot \mathrm{NH}_{2}$. The statement by Dewar [26] that 1,2,3-triphenylguanidine is a very strong base in comparison with 1 phenyl- and 1,3-diphenylguanidine is erroneous, as shown by the data in [22], which are in harmony with the relative effectiveness of the three bases when which are in harmony with the relative effectiveness

${ }^{16} \mathrm{As}$ already mentioned in this paper, 1,3- and 1,2,3-arylguanidines react in the same way as trialkylamines with bromophthalein magenta $\mathrm{E}$ in benzene. On the other hand, commercial samples of 1 -arylguanidines and $1-, 1,1-$, and $1,3-$ alkylguanidines resemble dialkylamines in their behavior with $\mathrm{BPM}-\mathrm{E}$ in ben. zene. These observations suggest that in the first-mentioned group of guanidines the positive charge on the cation is concentrated on one of the nitrogen atoms, although in the second group the positive charge is spread over at least two of the nitrogen atoms. (For a description and discussion of the behavior of BPM-E with di- and trialkylamines [6, p. 256-7]. 
two bases suggests that solvation by water may have a leveling effect on the basicities. Nevertheless, for the three guanidines considered in this paper (diphenyl-, triphenyl-, and di-o-tolyl-) there appears to be at least a rough proportionality between tha basicities in benzene and water.

In the introduction, two factors (solvation [5] and steric effects [9]) that may affect the strength of bases were discussed briefly. A more detailed discussion will show that the behavior of triethylamine is strikingly dependent on its environment. For some years it has been known [28] that when the hydrogen atoms in ammonia are replaced successively by ethyl groups, the first and second ethyl groups increase the basicity in water, but that the basicity is then markedly reduced by the third ethyl group. That is, the order of basic strengths in water is $\mathrm{NH}_{3}<\mathrm{Et}_{3} \mathrm{~N}<\mathrm{EtNH}_{2}<\mathrm{Et}_{2} \mathrm{NH}{ }^{17}$

The base-strengthening effect of the first and second alkyl groups is commonly regarded as a polar ("positive inductive") effect, and if no opposing factor were in operation, a third group should increase the basicity still further rather than decrease it.

The relative order of basicities found in water does not hold under all conditions. For example, Rimbach and Volk [29] studied the partition of nitric acid between the optically active base, cinchonidine, and a large number of optically inactive aliphatic and aromatic amines ${ }^{18}$ in aqueous ethanol (97.5\% ethanol by volume). A smaller number of bases was studied in 99.5-percent methanol. In some cases equilibrium was approached by adding cinchonidine to the nitrate of the inactive base, and in other cases the inactive base was added to cinchonidine nitrate; the results from the two methods did not differ significantly. From these measurements, the comparative strengths, or "avidities", of the various optically inactive bases were estimated. In every series of primary, secondary, and tertiary amines the monoderivative was found to be the strongest and the tri-derivative the weakest. More recently, Brown and Taylor $[30,31]$ have observed that with hydrogen chloride (gaseous) as the reference acid the order of basicity of the ethylamines (as shown by their tendency to combine with the acid) is the same as in water. However, with trimethylboron as the reference acid, the order is altered to $\mathrm{Et}_{3} \mathrm{~N}<\mathrm{NH}_{3}<$ $\mathrm{Et}_{2} \mathrm{NH}<\mathrm{EtNH}_{2}$, and with tri-t-butyl-boron there is a further change in order to $\mathrm{Et}_{3} \mathrm{~N}<\mathrm{Et}_{2} \mathrm{NH}<\mathrm{EtNH}_{2}$ $<\mathrm{NH}_{3}$. Thus, it appears that the order of strengths varies with the steric requirements of the reference acid, and that as these requirements increase the steric requirements of the base become more vital.

Brown [9, 31 to 33$]$ has suggested reasons why the ethylamines behave as hindered amines toward a rather bulky acid like trimethylboron. His detailed explanation may be summarized as follows: In ethylamine it seems likely that there are three stable configurations of the ethyl group, in one of which the methyl group is close to the free electron pair of the

\footnotetext{
17 The same order of strengths holds when the alkyl substituent is methyl, $n$-propyl, or isobutyl [28].

18 These included all of the methyl, ethyl, $n$-propyl, isobutyl, isoamyl, and benzylamines.
}

nitrogen atom. This configuration would be prohibited in an addition compound with trimethylboron, and the restriction of motion of the ethyl group would cause a certain amount of strain in the addition compound that would be relieved by dissociation of the compound. In an addition compound of diethylamine with trimethylboron there is only one possible configuration of the ethyl groups. The addition compound has almost no freedom of motion and is therefore under appreciable strain. Consequently it has a low degree of stability. In triethylamine one of the ethyl groups is adjacent to the free electron pair of the nitrogen. The amine cannot combine with trimethylboron without undergoing changes in the normal bond angles that result in a crowding of the ethyl groups. This explains why the addition compound is highly strained and extremely unstable.

The large steric requirements of triethylamine are evident not only in the instability of its addition compound with trimethylboron but in its relatively low rates of reaction with alkyl iodides in nitrobenzene solution [33]. In the reactions of amines with alkyl halides to give tetraalkylammonium halides, the first step is thought to be the formation of an addition compound ("activated complex") of the amine and the alkyl halide. On this hypothesis it is easy to see why the rate of formation of the tetraalkylammonium halide will be decreased if the steric requirements of the reactants are such as to impede the formation of the intermediate complex. Very recently 'Toy [34] has reported that the synthesis of tetraalkyl dithionopyrophosphates, by the action of a tertiary amine on a mixture of water and dialkyl thionochlorophosphate, appears to involve intermediate formation of a complex of the dialkyl thionochlorophosphate and the tertiary amine. With an unhindered amine a high yield of the desired product can be obtained, but with triethylamine and other hindered amines the yields are greatly reduced, in consonance with the experience of Brown and his coworkers in their studies of addition reactions. ${ }^{19}$

Brown has stated [32] that the ability of hindered amines such as triethylamine "to react with aqueous acids is not noticeably affected because of the low steric requirements of the proton." It should be borne in mind, however, that in water, as in other media, the proton does not have an independent existence. If it is not part of some neutral molecule, it is associated with molecules of solvent, and the steric requirements of various protogenic molecules and ions when reacting with bases are not equally great. As noted in one of our earlier publications ([6, p. 232]), the reactive proton in a molecule of bromophthalein magenta E probably forms a bridge between the phenolic oxygen and a neighboring bromine atom, so that the molecules do not undergo intermolecular

19 (Note added after completion of the manuscript.) Some Japanese workers [35] have studied the separation of various amines by distillation from aqueous or alcoholic solutions after partial neutralization of the hydrochlorides (hydroalcoholic solutions after partial neutralization of the hydrochlorides (hydro-
bromides) by alkali. Separation of aliphatic amines by ion-exchange resins was bromides) by alkali. Separation of aliphatic amines by ion-exchange resins was
also studied. The investigators failed to find a correlation between the order of also studied. The investigators failed to find a correlation between the order of
distillation, adsorbability by resins, and aqueous dissociation constants of amines, and commented that such examples of discrepancies between the apparent and true basicities have often been noticed. Their observations lend further support to the conclusions reached in this paper. 
association. There is no apparent reason for classifying bromophthalein magenta $\mathrm{E}$ as a hindered acid, but its steric requirements may be enough greater than those of the hydrated proton to account for lowered reactivity with a base as highly hindered as triethylamine. Furthermore, in benzene stabilization of the cation by solvation does not occur.

An earlier observation ([6, p. 256]) as to the behavior of bromophthalein magenta $\mathrm{E}$ when dissolved in some hindered alcohols seems pertinent to the present discussion. The magenta color of the solutions suggested that the indicator acid forms an addition compound with a hindered alcohol, but does not undergo ionization to form its blue anion, as it does in unhindered alcohols like ethanol. The explanation proposed was that the hydrogen bridge in the addition compound is shielded by hydrocarbon radicals in the alcohol, so that further solvation of the proton (necessary for ionization, according to the views presented in the introduction to this paper) is impeded. If this explanation is correct, it should follow that when BPM-E has combined with a reactive but highly hindered amine (eq 1 ), the addition compound $S_{1}$ will be less susceptible to attack by excess base than when the amine is not hindered. In support of this prediction, qualitative tests of the reaction of BPM-E with several aliphatic amines in benzene have indicated a greater tendency for the secondary reaction (eq 2) to occur when the amine contains one or more methyl groups than when the smallest substituent is an ethyl group. These considerations lead to the conclusion that while a hydrogen acid and an organic base may be sufficiently reactive and unhindered to form an addition compound $S_{1}$, it will not necessarily follow that $S_{1}$ will undergo ionization when an excess of the same base is added. Ionization may result, however, if a base of low steric requirements is added to the system. Such ideas are helpful in understanding why the addition of a very minute quantity of water has been found in some cases to have a marked effect on the ionization of acids and bases in nonaqueous solvents.

The results reported in this paper are of immediate practical interest in demonstrating how misleading the aqueous dissociation constants may be as a gage of the relative reactivities of bases in a nonaqueous solvent such as benzene. It could not have been predicted that diphenyl- and ditolylguanidine, which seem to be decidedly weaker than triethylamine in water, would be so reactive with bromophthalein magenta $\mathrm{E}$ in benzene. Although very limited in scope, the results indicate that water has a leveling effect on the strengths of bases as well as on those of acids, and that steric factors are important in the reactions of bases with protogenic acids as well as in their reactions with Lewis acids.

It can be predicted that when the strengths of a series of bases are compared in different media, a greater number of irregularities will be observed than in a similar comparison of the strengths of hydrogen acids. Although hydrogen acids may differ somewhat in steric requirements and their behavior may be modified by intramolecular hydrogen bonding, they have more in common from a structural standpoint than do the organic bases, which may owe their basicity to nitrogen, oxygen, or various other atoms, as well as vary over a wider range in their steric requirements.

\section{References}

[1] A. Hantzsch, Z. Elektrochem, 29, 221 (1923); 30, 194 (1924); see also L. P. Hammett, J. Am. Chem. Soc. 50, 2666 (1928)

[2] H. von Halban, Z. Elektrochem. 29, 434 (1923); 30, 601 (1924).

[3] P. Walden, Salts, acids, and bases: Electrolytes: Stereochemistry (McGraw-Hill Book Co., Inc., New York, N. Y., 1929)

[4] J. N. Brønsted, Chem. Rev. 5, 231 (1928).

[5] A. F. Trotman-Dickenson, J. Chem. Soc. (London) 1293 (1949).

[6] M. M. Davis and P. J. Schuhmann, J. Research NBS 39, 221 (1947) RP1825.

[7] M. M. Davis, P. J. Schuhmann, and M. E. Lovelace, J. Research NBS 41, 27 (1948) RP1900.

[8] M. M. Davis and H. B. Hetzer, J. Research NBS 46, 496 (1951) RP2219.

[9] H. C. Brown, Science 103, 385 (1946); see also [30 to 33] in this paper.

[10] G. N. Lewis, J. Franklin Inst. 226, 293 (1938).

[11] R. P. Bell, Quarterly Rev. Chem. Soc. (London) I, 113 (1947).

[12] S. J. O'Brien, C. L. Kenny, and R. A. Zuercher, J. Am. Chem. Soc. 61, 2504 (1939).

[13] M. M. Davis and E. A. McDonald, J. Research NBS 42, 595 (1949) RP1997.

[14] A. A. Maryott, J. Research NBS 41, 7 (1948) RP1897.

[15] A. A. Maryott, J. Research NBS 38, 527 (1947) RP1794.

[16] W. F. K. Wynne-Jones, J. Chem Soc. (London) 795 (1931).

[17] C. A. Kraus, J. Phys. Chem. 43, 231 (1939); see also discussion by M. Kilpatrick and K. Fajans, J. Phys. Chem. 43, 288 (1939).

[18] E. E. Sager and I. J. Siewers, J. Research NBS 45, 489 (1950) RP2162.

[19] H. Fleisher, Ind. Eng. Chem., Anal. Ed. 15, 742 (1943).

[20] L. Metz, Z. Elektrochem. 34, 292 (1928).

[21] T. L. Davis and R. C. Elderfield, J. Am. Chem. Soc. 54, 1499 (1932)

[22] N. F. Hall and M. R. Sprinkle, J. Am. Chem. Soc. 54, 3469 (1932); see also N. F. Hall, J. Am. Chem. Soc. 52, 5115 (1930).

[23] B. Neivelt, E. C. Mayo, J. H. Tiers, D. H. Smith, and G. W. Wheland, J. Am. Chem. Soc. 73, 3475 (1951).

[24] S. J. Angyal and W. K. Warburton, J. Chem Soc. (London) 2492 (1951).

[25] L. Pauling, The nature of the chemical bond (Cornell Univ. Press, Ithaca, N. Y., 2d ed., 1940).

[26] M. J. S. Dewar, The electronic theory of organic chemistry, p. 95 (Oxford Univ. Press, New York, N. Y., 1949).

[27] G. D. Kratz, H. H. Young, Jr., and I. Katz, Ind. Eng. Chem. 41, 399 (1949).

[28] G. Bredig, Z. phys. Chem. 13, 289 (1894).

[29] E. Rimbach and H. Volk, Z. phys. Chem. 7\%, 385 (1911).

[30] H. C. Brown, J. Am. Chem. Soc. 67, 503 (1945).

[31] H. C. Brown and M. D. Taylor, J. Am. Chem. Soc. 69, 1332 (1947).

[32] H. C. Brown and S. Sujishi, J. Am. Chem. Soc. 70, 2878 (1948).

[33] H. C. Brown and N. R. Eldred, J. Am. Chem. Soc. 71, 445 (1949).

[34] A. D. F. Toy, J. Am. Chem. Soc. 73, 4670 (1951).

[35] Kyosuke Tsuda and Tetsuro Matsumoto, J. Pharm. Soc. Japan 67, 107, 236 (1947); Kyosuke Tsuda, Tetsuro Matsumoto, and Takahiro Nakamura, J. Pharm. Soc. Japan 67, 115 (1947); Kyosuke Tsuda and Takahiro Nakamura, J. Pharm. Soc. Japan 67, 117 (1947). Through Chem. Abstracts 45, 9465 (1951).

Washington, February 7, 1952. 